\title{
Where two giants meet: the first records of Sphodromantis viridis in Sicily and Greece and the spread in Europe of Hiero- dula tenuidentata (Insecta Mantoidea) show new crossroads of mantids in the Mediterranean
}

\author{
Roberto Battiston', Simone Andria', Domenico Borgese², William Di Pietro' \& Alberto Manciagli² \\ ${ }^{1}$ World Biodiversity Association Onlus, c/o Museo Civico di Storia Naturale, Lungadige Porta Vittoria 9, Verona, Italy \\ ${ }^{2}$ Dipartimento di Scienze Biologiche, Geologiche e Ambientali dell'Università degli Studi di Catania, Via A. Longo, \\ 19, Catania, Italy
}

\begin{abstract}
The first presence records of the Giant African Mantis Sphodromantis viridis (Forskål, 1775) (Insecta Mantoidea) are reported for Sicily and Greece, with new evidences on the humanmediated spreading of this species in the Mediterranean area. In Greece, Sphodromantis viridis meets the distribution of the Giant Asian Mantis Hierodula tenuidentata (Saussure, 1869), and these two mantids have been recorded together in the same locality. Some single records from France and Corsica also open the possible expansion of this species in more northern regions. These different spreading dynamics, taking place in the Mediterranean area, in a fast-evolving scenario, are here discussed.
\end{abstract}

KEY WORDS Giant mantises, distribution, new records, human impact, invasive species.

Received 10.07.2020; accepted 23.08.2020; published online 30.09.2020

\section{INTRODUCTION}

During the last few years, the mantid populations in the Euro-Mediterranean area have significantly changed. From one side the commercial routes from Asia to Europe have been used by at least two species of Giant Asian Mantids: Hierodula tenuidentata (Saussure, 1869) and H. patellifera (Serville, 1839) to spread in Europe (Battiston et al., 2018, 2020; Moulin, 2020, Schwarz \& Ehrmann, 2018) creating well-settled populations in different countries. If $H$. patellifera appears now well settled in northern Italy and Provence, $H$. tenuidentata is spreading fast in the Balkans reaching most of the Greek islands and northern Italy. Other smaller populations or single individuals of other mantid species have been recorded in Europe in a fast-changing scenario (Schwarz \& Ehrmann, 2018).

The Giant African Mantis Sphodromantis viridis (Forskål, 1775) is also spreading in the Mediterranean area with particularly interesting dynamics. This xerothermophilous but very adaptable species is widely distributed from the sub-Saharan regions of northern Africa to the Middle East. Its presence in Europe has been limited in historical times to Southern Spain with the western subspecies $S$. viridis vischeri Werner, 1933. In 2004, this mantid appears in the Balearic island of Mallorca (Cantelles \& Alomar, 2006) and later in Sardinia: first in a small island in the northern archipelago and then in the mainland with many different observations from North to South (Battiston et al., 2017, 2019). From a first morphological analysis (Battiston et al., 
2017) these populations seem to be linked to the Hiberic subspecies, while the presence of this species in some islands in the southern Mediterranean area is probably related to the North African subspecies $S$. viridis barbara and $S$. viridis viridis as supposed by La Greca (1966). Despite its wide distribution this species is a poorly known insect and its dynamics are still far to be well understood, but while $\mathrm{Hi}$ erodula seems to follow more global commercial routes from East to West, Sphodromantis seems to reflect a more local-Mediterranean dynamic, too fast and sudden to be natural but opportunistic if artificial. Thus far, these two genera, very similar in many aspects of their biology, have not yet met each other, but some new records here presented may confirm the first contact.

\section{MATERIAL AND METHODS}

Literature records have been examined together with digital databases (iNaturalist, GBIF) and social media. In this case, some records previously identified as Hierodula or Mantis religiosa (Linnaeus 1785). The records and specimens from Sicily have been observed and collected during random samplings. Five site inspections have been made in the collecting locality to verify its presence and evaluate its density. The records from Greece have been identified from several detailed photographs sent by the observers.

\section{RESULTS}

Sphodromantis viridis (Forskål, 1775) new presence records (Figs. 1, 2): Italy. Sicily, Catania (37³2'30.6”N 1505'00.6”'E), 19.X.2019, 1 adult female, 2 oothecae. Urban park, degraded garrigue environment.

Greece (Figs. 3, 4). Patronikoleika (3742'23.3'N 2119'16.7'E), 29.IX.2019, Murru obs., 1 adult male; touristic beach, residential environment. Glifada (3753'03.4”N 2344'48.7''E), 12.X.2019, Zafeiriou obs, 1 adult female; urban environment. Alsoupoli (3801'56.7'N 2346'45.0’'E), 29.VIII.2020, Vasilis obs, 1 sub-adult; urban environment.

France. Biscarrosse (44⒉ $\left.7^{\circ} 54.5^{\prime} \mathrm{N} 1^{\circ} 13^{\prime} 49.7^{\prime} \mathrm{W}\right)$ 12.XI.2018. iNaturalist record: 18353062 , 1 adult female. Coastal areas near touristic residences.
Corsica, Ile Rousse (42॰38'02.4’N 856'15.1’'E), 21.10.19. iNaturalist record: 34697875,1 adult male. Touristic beach, residential environment.

\section{DISCUSSION}

After the first update on its distribution (Battiston et al., 2017), S. viridis confirmed a tendency to spread quickly in the Mediterranean basin. This species seems to be very adaptable to different environments even to very anthropized ones. Its presence in urban or residential environments and the speed of the spreading over so distant localities, especially in the islands, support the hypothesis of human-mediated transport at the global level. The distribution limits of this species inside the Mediterranean Climate Domain seem to be still respected, even if the distribution is expanding to the north. The presence of $S$. viridis in Sicily, where it has never been recorded before, is attested by the presence of a gravid female and two oothecae, one of which clearly older than 2019, with deterioration, exfoliation and damage. The mantid individual was found in the small natural reserve Timpa di Leucatia, on the border of a wetland near a degraded garigue environment (where the oothecae were found), surrounded by the large urban area of Catania. Besides the small natural spot, the area is degraded and very anthropized without ecological corridors with other natural areas and can be defined as an urban park. We can exclude the arrival of this specie as a natural expansion of its distribution in the wild. The presence of stable continental populations in Europe, outside the Iberian Peninsula, still needs to be verified from the few single specimens here recorded. In France, this species should be still considered as occasional and vagrant, but the single records here reported open the possibility of an expansion of this adaptable species in more northern regions that should be investigated. A stable presence seems now to occur in Greece, where the records of both males and females in different years and localities suggest, with more confidence, the possible existence of small populations in the mainland in Attica and with possible records also in the islands: the Peloponnese, and a juvenile of cf. Sphodromantis reported in Crete (iNat: 60785200, dated 2014). The area of Athens with the records of Glifada and Alsoupoli, 


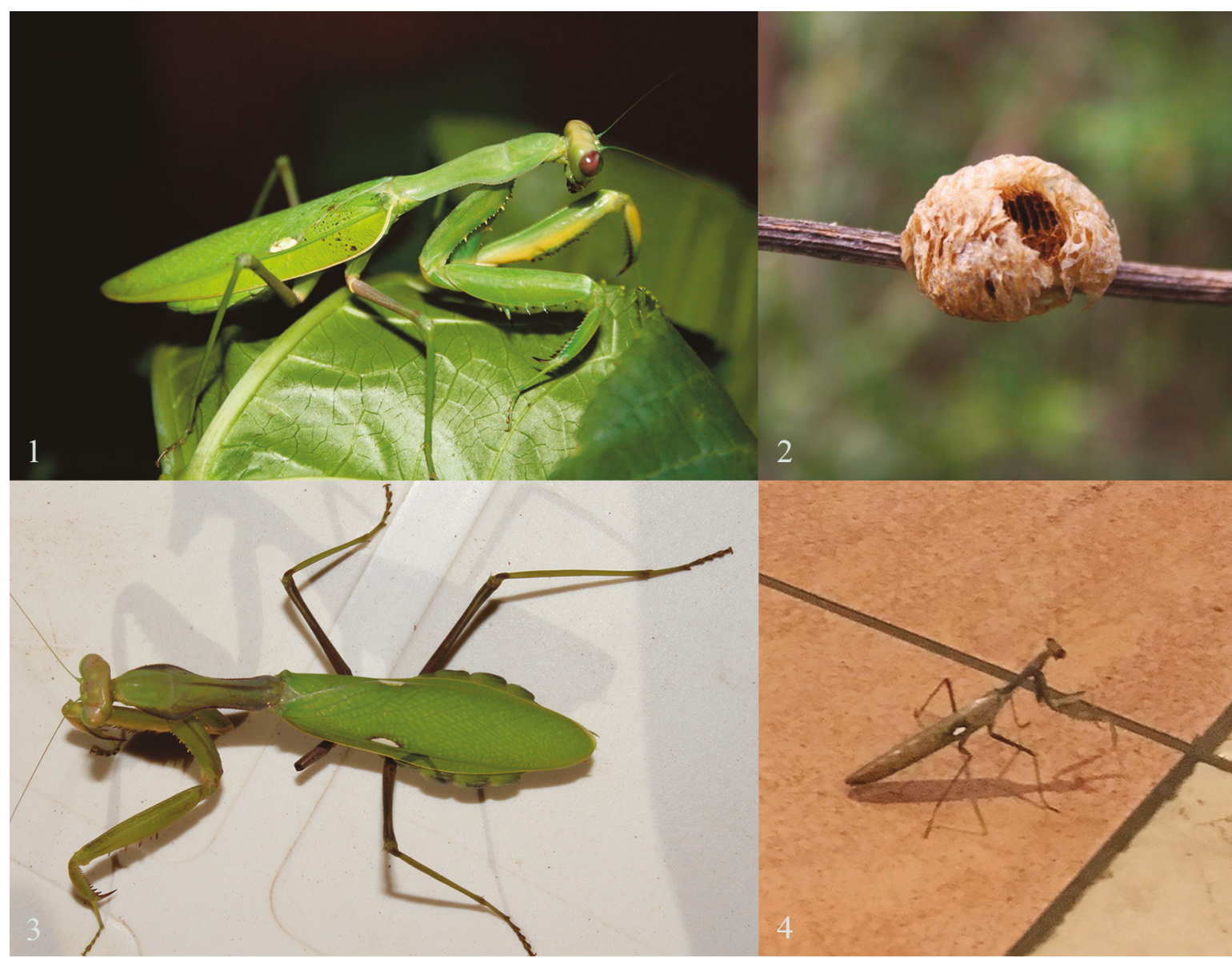

Figures 1, 2. Sphodromantis viridis from Italy: adult female (Fig. 1) and ootheca (Fig. 2), photos D. Borgese. Figures 3, 4. Sphodromantis viridis from Greece: adult female from Glifada (Fig. 3, photo S. Zafeiriou) and male from Patronikoleika (Fig. 4, photo A. Murru).

appears interesting because iNaturalist reports also many presence record of Hierodula other than Sphodromantis. In the same locality of Patronikoleika, in the Peloponnese, Mantis religiosa is also reported (iNat: 31465138).

The presence of Sphodromantis here sets up the first meeting point with Hierodula and their interaction should be evaluated in the near future. This should be evaluated also in Provence where this latter genus is present with the species $H$. patellifera Serville 1839 (Moulin, 2020). This appears to be a good time for these mantids to spread and increase their distribution, but while Hierodula arrived from far eastern countries, Sphodromantis was already present in the Mediterranean, so why now? Mediterranean Climate Domain is currently evolving and shifting together with the Arid Climate Domain. Projected changes in climate param- eters (Barredo et al., 2018) indicate a transition towards hotter and drier conditions and, consequently, the establishment and spread of invasive alien species (Hellmann et al., 2008). Sphodromantis with its confidence with anthropized environments and human-mediated transport is here an adaptable and opportunistic species that should be monitored in the future, especially in its impacts on the local ecosystems and on other native or alien mantids species.

\section{ACKNOWLEDGEMENTS}

We would like to thank Giorgio Alexander Murru (England), Savvas Zafeiriou and Stergios Vasilis (Greece) for sharing records and detailed information on the presence of these mantids in Greece and 
the community of iNaturalist for sharing updated records of these insects. We are particularly grateful to the World Biodiversity Association (Verona, Italy) for supporting this study.

\section{REFERENCES}

Barredo J.I., Mauri, A., Caudullo, G. \& Dosio A., 2018. Assessing Shifts of Mediterranean and Arid Climates Under RCP4.5 and RCP8.5 Climate Projections in Europe. Pure Applied Geophys, 175: 3955-3971. https://doi.org/10.1007/s00024-018-1853-6

Hellmann J.J., Byers J.E., Bierwagen B.G. \& Dukes J.S., 2008. Five potential consequences of climate change for invasive species. Conservation Biology, 22: 534-543. https://doi.org/10.1111/j.1523-1739.2008. 00951.x.

Battiston R., Picciau L., Fontana P. \& Marshall J., 2010. The Mantids of the Euro-Mediterranean Area. WBA Handbooks 2, Verona, 240 pp.

Battiston R., Andria S. \& Ruzzante G., 2017. The silent spreading of a giant mantis: a critical update on the distribution of Sphodromantis viridis (Forskål, 1775) in the Mediterranean islands (Mantodea: Mantidae). Onychium, 13: 25-30. https://doi.org/10.5281/ zenodo. 546318

Battiston R., Leandri F., Di Pietro W. \& Andria S., 2018. The giant Asian Mantis, Hierodula tenuidentata, spreads in Italy: a new invasive alien species for the European fauna? Biodiversity Journal, 9: 399-404. https://doi.org/10.31396/Biodiv.Jour.2018.9.4.399.404

Battiston R., Leandri F., Di Pietro W. \& Andria S., 2019. Mantis, Hierodula e Sphodromantis: aggiornamento su conoscenze e identificazione delle mantidi (Mantodea: Mantinae) native ed aliene presenti in Italia. Pianura - Scienze e storia dell'ambiente padano 38: 86-96. http://bibliotecadigitale.provincia.cremona.it/ pianura/download/Pianura_38.pdf

Canyelles X. \& Alomar G., 2006. Sobre la presència de Sphodromantis viridis (Forskål, 1775) (Dictyoptera, Mantoidea) a Mallorca. Bolletí de la Societat d'Història Natural de les Balears, 49: 83-87.

La Greca M., 1966. Sulle Sphodromantis del gruppo viridis dell'Africa settentrionale ed occidentale. Eos, 42: 493-516.

Inaturalist, 2020. https://www.inaturalist.org. Accessed on: 2020-07-06.

Moulin N., 2020. When Citizen Science highlights alien invasive species in France, the case of Indochina mantis, Hierodula patellifera (Insecta, Mantodea. Biodiversity Data Journal 8: e46989. https://doi. org/10.3897/BDJ.8.e46989

Ruzzante G. \& Leo P., 2012. 116. Sphodromantis viridis (Forskål, 1775) (Mantodea Mantidae). Quaderno di Studi e Notizie di Storia Naturale della Romagna, 35: 173-174.

Schwarz C. \& Ehrmann R., 2018. Invasive Mantodea species in Europe. Articulata, 33: 73-90. 